\title{
Plasma Coating and Surface Modification of Amorphous Carbon for Biomedical
} Applications

Maguire, PD., Okpalugo, TIT., \& Ahmad, I. (2006). Plasma Coating and Surface Modification of Amorphous Carbon for Biomedical Applications. Materials Science Forum, 518, 477-484. http://www.scientific.net

Link to publication record in Ulster University Research Portal

\section{Published in:}

Materials Science Forum

Publication Status:

Published (in print/issue): 01/01/2006

\section{Document Version}

Publisher's PDF, also known as Version of record

\section{General rights}

Copyright for the publications made accessible via Ulster University's Research Portal is retained by the author(s) and / or other copyright owners and it is a condition of accessing these publications that users recognise and abide by the legal requirements associated with these rights.

\section{Take down policy}

The Research Portal is Ulster University's institutional repository that provides access to Ulster's research outputs. Every effort has been made to ensure that content in the Research Portal does not infringe any person's rights, or applicable UK laws. If you discover content in the Research Portal that you believe breaches copyright or violates any law, please contact pure-support@ulster.ac.uk. 


\title{
Plasma Coating and Surface Modification of Amorphous Carbon for Biomedical Applications
}

\author{
P.D. Maguire ${ }^{a}$, T.I.T. Okpalugo and I. Ahmad \\ Nanotechnology Research Institute and N. Ireland Bio-Engineering Centre \\ University of Ulster, Newtownabbey, Belfast, BT37 0QB, Ireland \\ apd.maguire@ulster.ac.uk
}

Keywords: Amorphous Carbon, Interfacial Layers, Medical Devices, Plasma Coating, Raman Spectroscopy.

\begin{abstract}
Amorphous carbon coatings for implantable medical devices require high mechanical strength, adhesion and uniform biocompatibility response across the devices. Investigation of a-C:H properties and structure variation with thickness and substrate material provides valuable insight into requirements for device coating. A number of devices are coated and the effect of interfacial layers, film doping and the spatial variation in quality is investigated.
\end{abstract}

\section{Introduction}

In biomedical applications, surface modification increases the design flexibility in device manufacture by allowing engineers to choose materials with desirable bulk properties and then tailor the surface to the surrounding environment. In this paper examples from our recent research on biocompatible amorphous carbon deposition will be used to highlight some important aspects of plasma operation, design and characterisation in materials development. Amorphous carbon represents a class of materials with a range of optical, mechanical and electrical properties that lie somewhere between those of graphite, polymers and diamond, depending on deposition conditions. Two technologically important types are hard hydrogen-containing amorphous carbon $(\mathrm{a}-\mathrm{C}: \mathrm{H})$ and very hard tetragonal amorphous carbon $(\mathrm{t}-\mathrm{aC})$, which is hydrogen-free. The latter has received considerable theoretical attention because of its superior properties but deposition requires complex and expensive equipment and film deposition is often limited to very thin layers $(<100 \mathrm{~nm})$ on flat substrates due to the high internal stress. Therefore a-C:H is considered the more appropriate choice in biomedical applications, for example in haemocompatible or reduced wear coatings on implantable medical devices, such as hip joints and stents. The basic characterisation parameters for such films are the ratio of $\mathrm{sp}^{3}$ (diamond-like) bonding to $\mathrm{sp}^{2}$ (graphitic) bonding and the hydrogen content. For hard diamond-like films, the $\mathrm{sp}^{3} / \mathrm{sp}^{2}$ ratio should be maximised and H-content minimised.

Much of our research into the growth and characterisation of such films has been limited to deposition onto high quality, planar silicon substrates. Material analysis has involved a wide range of high-resolution techniques such as NEXAFS, XPS and Raman spectroscopy, to determine $\mathrm{sp}^{3} / \mathrm{sp}^{2}$ structure, XRR and ellipsometry for refractive index and density, nanoindentation and AFM for mechanical and topological properties etc. However, for practical applications we need to deposit films onto other substrate materials, many of which are not conducive to carbide formation - a precursor to amorphous carbon growth. Furthermore many devices requiring coating are irregularly shaped with sizes varying from a few millimetres (e.g dental implants, stents) to tens of cm (e.g hip joints, heart valves). These coatings must be of uniform high quality, without pinholes or shadowing. The impact of these factors on the capability of the plasma to produce uniform quality coatings is evident in a number of ways, namely: (i) is the sheath electric field around the device uniform, allowing equal ion flux and energy to all parts, (ii) how is electrical connection to be made without shadowing parts of the device from the coating and (iii) how can the plasma system handle the coating of multiple devices simultaneously. Solutions are likely to be application specific, involving system design, the use of interlayers and multilayers and the incorporation of dopants, 
among others. In this paper, a brief summary of our previous work on a-C:H films deposited on $\mathrm{Si}$ wafers will be followed by a comparison of the structure with that of films deposited on metal and polymer substrates. The impact of substrate materials, the use of interlayers and dopants on electrical, mechanical and biological properties will then be presented, with particular relevance to device and plasma considerations. The coating of two implantable devices, the catheter guidewire and the cardiovascular stent, will then be used to highlight particular difficulties in device coating and offer some insight into future requirements for biocompatible coating processes.

Guidewires are used for introducing and placing micro-interventional devices in the body. It consists of a stiff spring wound stainless steel shaft, to provide support for catheter delivery. The steel is covered in a low friction (high lubricity) polymer coating, typically PTFE, to ease advancement through the tortuous anatomy and stented vasculature. Amorphous carbon has been proposed as a replacement for the (spray coated) polymer and the main requirements are low friction and a stable bio-inert coating with total metal coverage, particularly within the spring interstices of the main shaft. A stent is a flexible metal coil or open-mesh tube that is surgically inserted into a narrowed artery, then expanded and pressed into the vascular wall at up to 10-20 atm pressure, providing a scaffold to hold the artery open. The diameter is increased by more than a factor of two post-expansion. Stents have traditionally been metallic because of the necessary mechanical requirements. Metal surfaces, however, are highly thrombogenic. The ideal stent therefore must meet stringent thrombogenicity, biocompatibility and structure requirements and amorphous carbon has shown potential as biocompatible and as a barrier to metal ion diffusion

\section{Experimental}

Amorphous carbon was deposited via three systems: $13.56 \mathrm{MHz}$ RF planar PECVD (Planar and stents), RF Coaxial PECVD (guidewires) and RF Vertical PECVD (guidewires). Undoped a-C:H and silicon-doped a-C:H:Si (Si-DLC) films were deposited with a bias voltages of $300-400 \mathrm{~V}$, the former using a mixture $\mathrm{Ar}: \mathrm{C}_{2} \mathrm{H}_{2}$ (1:1.5), while Si-doping was obtained by adding $\mathrm{Si}\left(\mathrm{CH}_{3}\right)_{4}(\mathrm{TMS})$ vapour. For cell and platelet studies, a-C:H:Si films were grown at $400 \mathrm{~V}$ bias voltage, with an argon-acetylene gas mixture (ratio 1:2) and variable flow tetramethylsilane (TMS) vapour for silicon doping between $5 \%$ and $11 \%$ concentration, on argon-cleaned silicon wafers. Films were annealed for $2 \mathrm{~h}$, up to $600{ }^{\circ} \mathrm{C}$ under flowing nitrogen. A-C:H films were deposited onto stainless steel stents using a 2:1 $\mathrm{C}_{2} \mathrm{H}_{2} / \mathrm{Ar}$ mixture, at pressures between 2 and $10 \mathrm{mTorr}$ for $300 \mathrm{sec}$ at electrode bias voltages of $\sim 350 \mathrm{~V}$. These conditions on planar substrates result in good quality DLC layers with thickness values between $50-100 \mathrm{~nm}$. The stents were $15 \mathrm{~mm}$ in length with an unexpanded diameter of $1.5 \mathrm{~mm}$. After expansion this diameter increased to $4.5 \mathrm{~mm}$ maximum. Indentation tests were performed using a Nanoindenter XP (NanoInstruments Inc) with a highresolution dynamical contact module (DCM) head. Hardness $(\mathrm{H})$ and Young's modulus (E) was extracted using the continuous stiffness measurement technique. For the $100 \mathrm{~nm}$ samples, the minimum contact depth was $\sim 50 \%$ of film thickness and hence the influence of the substrate cannot be excluded. A Burleigh ARIS-3300 AFM was used to measure the film thickness. An ISA-Labram with a $50 \mathrm{~mW}$ argon ion laser was used to obtain Raman spectra, the D and G peak intensities were extracted using a double-Gaussian fit and by comparison with data in [1], an estimate of the $\mathrm{sp}^{2} / \mathrm{sp}^{3}$ bonding could be obtained. Current-voltage (I-V) measurements were carried out on the films using a metal-semiconductor-metal (MSM) sandwich with a Keithley model 485 digital picoammeter, details of which are given elsewhere [2]. Human Microvascular Endothelial (HMEC) cells were grown as monolayers in tissue culture flasks at $37{ }^{\circ} \mathrm{C}$ under $5 \% \mathrm{CO}_{2} / 95 \%$ air. Cells were used when they were about confluent and under exponential growth phase, and $\sim 4 \times 10^{5}$ cells $/ \mathrm{ml}$ were seeded, for $6 \mathrm{~h}$ on top of the a-C:H and a-C:H:Si samples and placed inside petri-dishes, with uncoated samples used as control. Whole blood PRP (platelet rich plasma) and PPP (Platelet poor plasma) was mixed to $\sim 1 \times 10^{8}$ cells $/ \mathrm{ml}$ and seeded on top of the a-C:H and a-C:H:Si samples.. Incubation was carried out at $37{ }^{\circ} \mathrm{C}$ in $5 \% \mathrm{CO}_{2}$ for $30 \mathrm{mins}$. After fixing and drying, the cells/platelet treated samples were gold-coated $(\sim 30 \mathrm{~nm})$ and imaged in a Hitachi S-3200N SEM (SE-mode, $5.0 \mathrm{kV}, \mathrm{x}$ $200 \mathrm{mag}$ ) and cells/platelets counted using the UTHSCSA, ImageTool program. The image area 
was $500 \times 500 \mu \mathrm{m}$ and images were analysed at several sites across each sample.

\section{Results and Discussion}

Planar substrates. The growth of a-C:H from hydrocarbon based plasmas (e.g. $\mathrm{Ar}+\mathrm{C}_{2} \mathrm{H}_{2}$ or $\mathrm{CH}_{4}$ ) depends on complex interactions involving: (i) ions $\left(\mathrm{Ar}^{+}, \mathrm{C}^{+}, \mathrm{C}_{\mathrm{x}} \mathrm{H}_{\mathrm{y}}^{+}, \mathrm{H}^{+}\right)$accelerated by the electric field across the sheath, between plasma and substrate, and bombarding the growing film causing etching, reconstruction of the lattice bonds, defect creation and the appearance of surface adsorption sites and (ii) the adsorption of radicals (e.g. $\mathrm{C}_{2} \mathrm{H}, \mathrm{CH}_{3}, \mathrm{H}$ ) at such sites leading to film growth. Therefore, in simple terms, the plasma needs to be able to dissociate the hydrocarbon gas and to accelerate the different ions. Beyond that however, more detailed knowledge is rare and we have found that across a wide range of plasma conditions, the plasma input parameters (power, pressure, gas mixture) have limited impact on film properties $\left(\mathrm{sp}^{3} / \mathrm{sp}^{2}, \mathrm{H}\right.$-content). The hardest films are generally obtained within a (negative) substrate bias window of $200-350 \mathrm{~V}$ at pressures of 10 mTorr or less. Low bias/high pressure leads to soft polymeric films (with high $\mathrm{H}$ ), while high bias results in low $\mathrm{sp}^{3} / \mathrm{sp}^{2}$, soft, graphite-like films. Considering bias and pressure together implies that the energy of ion bombardment is a significant factor, however it is not clear how these parameters affect the dissociation and transport of species to the substrate.

Raman spectroscopy is used as a useful tool for a-C:H structure analysis, for example extracting the ratio of the D-peak to G-peak heights $\left(\mathrm{I}_{\mathrm{D}} / \mathrm{I}_{\mathrm{G}}\right)$ from spectra, indicates relative changes in the $\mathrm{sp}^{3} / \mathrm{sp}^{2}$ ratio. In Fig. 1, we observe a-C:H on Si substrates with a low $\mathrm{I}_{\mathrm{D}} / \mathrm{I}_{\mathrm{G}}$ ratio $(<0.4)$, for thicknesses over $\sim 20 \mathrm{~nm}$ and by comparison with more detailed analysis using NEXAFS [3,4], we have estimated the $\mathrm{sp}^{3} / \mathrm{sp}^{2}$ ratio to be $\sim 50 \%$, which is towards the high end of that normally achievable with a-C:H. This structure remains reasonably constant, even for quite thick films $(\sim 1$ $\mathrm{um})$. For other, metal, substrates, $\mathrm{sp}^{3} / \mathrm{sp}^{2}$ is lower with strong thickness dependence. The best-case metals are stainless steel and Al, where the thickness dependence is negligible below $\sim 200 \mathrm{~nm}$. We note a change in properties after the initial stages of growth $(<20 \mathrm{~nm})$. Below this, the Raman spectra of a-C:H on $\mathrm{Si}$ appears to indicate a greater $\mathrm{H}$-content, i.e. films are probably soft and polymeric, whereas on metal, a lower H-content, more graphitic film is likely. The sub-20nm film structure is difficult to determine and is currently undergoing more detailed analysis but a number of points are worth noting. The difference in structure between $\mathrm{Si}$ and other substrates is linked to the differences in density, carbon ion penetration and initial carbide bond formation between metals and $\mathrm{Si}$. The $20 \mathrm{~nm}$ initial layer is approximately the penetration depth of hydrogen, i.e. beyond 20 $\mathrm{nm}$ the carbon film growth is isolated from the substrate. However, there appears to be a correlation between initial growth and subsequent structure, up to about $200 \mathrm{~nm}$. While the Raman spectra can indicate relative changes in structure, electrical measurements are useful for highlighting how the structure impacts on film properties.

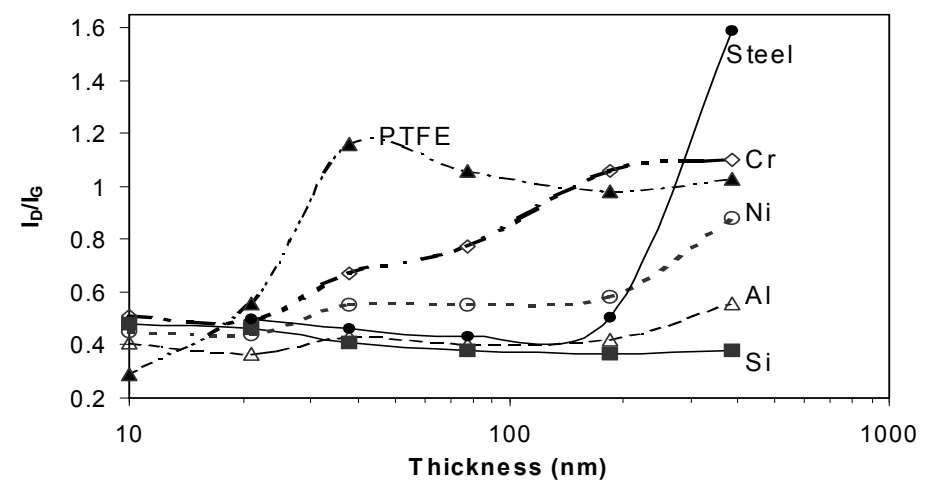

Fig. 1 Raman $\mathrm{I}_{\mathrm{D}} / \mathrm{I}_{\mathrm{G}}$ ratio for a-C:H films, of various thicknesses, deposited onto silicon, metal and polymer substrates.

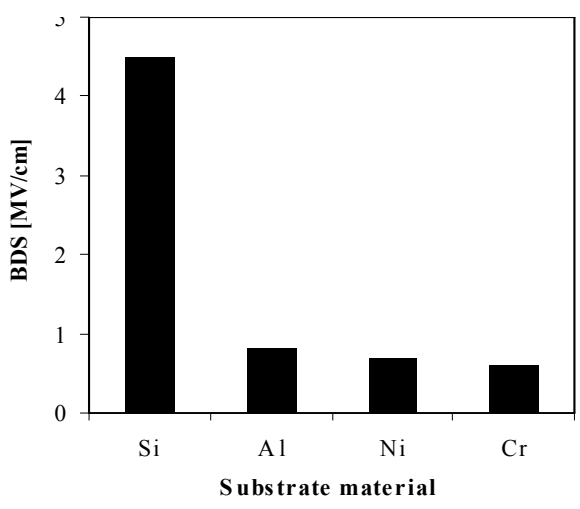

Fig. 2 Electrical breakdown strength of $50 \mathrm{~nm}$ a-C:H films on different substrates. 
In Fig. 2, the plot of breakdown strength shows the reduction in a-C:H quality for deposition onto metal. Possible solutions, currently under investigation, include the use of graded silicon interfaces between metal and a-C:H and the fabrication of multilayers of $a-C_{x} S_{y}: H, a-C: H, t-a C$ and a-C (sputtered). In the interim, the coating of stainless steel devices includes a $10 \mathrm{~nm}-20 \mathrm{~nm}$ silicon-rich interfacial layer. For body-implantable device coating, there are a number of stringent mechanical and biological criteria.

In the former, the devices after subjected to extreme mechanical working, post-deposition. For guidewires, this can mean winding the wire into a tight spring while for stents, after insertion, the stent diameter is expanded (x3) inside the artery. Both the film interfacial bonding and the film bulk must withstand such expansion and stressing. Initial work on such devices (see below) highlighted the difficulty and hence the a-C:H were doped with silicon $(<10 \%)$ to improve their mechanical characteristics. The effect of $\mathrm{Si}$ incorporation on microstructure is detailed in [5-9]. Devices must also offer (i) a protective barrier to metal ion transport from the substrate, implying $100 \%$ coverage above a minimum thickness, (ii) must withstand exposure to body fluids and must present a bio-inert or bio-favourable surface to blood-flow. Initial bio-fluid and standard corrosion studies have been undertaken. For simple biocompatibility testing, the attachment of platelets and endothelial cells to a-C:H surfaces can provide a screening-level guide, whereby we seek low platelet and improved endothelial cell attachment compared to uncoated steel. However, since uniform quality cannot be guaranteed on all areas of the device, we need to determine the biocompatibility sensitivity to changes in a-C:H structure and properties. To simulate these changes we have used annealing, up to $600{ }^{\circ} \mathrm{C}$, of undoped and si-doped a-C:H. The effect of annealing is controlled reduction in $\mathrm{sp}^{3} / \mathrm{sp}^{2}$ and the suspected removal of hydrogen

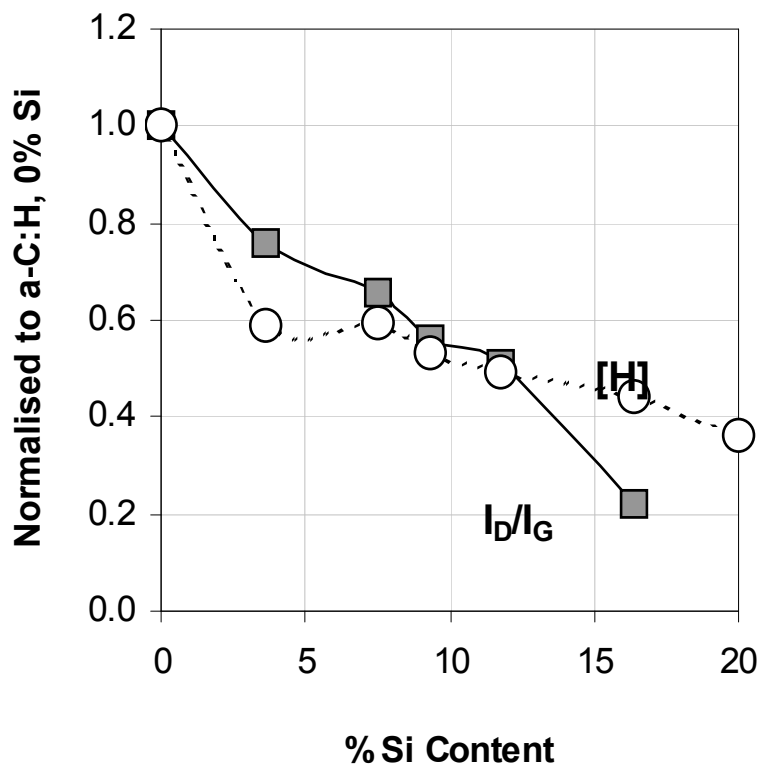

Fig. 3 Hardness $(\mathrm{H})$, Raman $\mathrm{I}_{\mathrm{D}} / \mathrm{I}_{\mathrm{G}}$, variation with $\% \mathrm{Si}$, normalised to their values at $0 \% \mathrm{Si}$, which are $25 \mathrm{GPa}, 0.41,0.81,0.9$ respectively.

Relative parameter values, from hardness and Raman are shown in Fig. 3, against Si content, normalized with respect to undoped DLC values. Hardness $(H)$ (and Young's modulus $(E)$ ) decreases with $\mathrm{Si}$ addition, from $\sim 25 \mathrm{GPa}$ (undoped) to $\sim 9 \mathrm{GPa}(20 \% \mathrm{Si})$ and it appears that $\mathrm{Si}$ doping promotes the formation of $\mathrm{sp}^{3}$ bonding in the a-C:H films with Raman $\mathrm{I}_{\mathrm{D}} / \mathrm{I}_{\mathrm{G}}$ falling from 0.41 (undoped) to $\sim 0.1(16 \% \mathrm{Si})$. Although higher $\mathrm{sp}^{3}$ content is usually associated with increased hardness, Si doping can also promote the incorporation of hydrogen, enhancing the formation of a polymeric $\operatorname{sp}^{3} \mathrm{CH}_{n}(\mathrm{n}>1)$ structure leading to reduced stress and lower hardness. The high $\mathrm{H}$ concentrations in Si-containing films are manifested by the increasing slope of the Raman spectrum background [10].

In initial studies we have observed favourable interaction between platelets [11] and Human Microvascular Endothelial Cells (HMEC) with undoped a-C:H [12]. For undoped a-C:H films, without annealing, the HMEC attachment is similar to that of the uncoated silicon wafer. However, 
with increasing anneal temperature, cell attachment increases up to a maximum at $300{ }^{\circ} \mathrm{C}$ and falls thereafter, Fig. 4(a). The platelet attachment follows the opposite trend, with a minimum at $200{ }^{\circ} \mathrm{C}$.

For two values of $\mathrm{Si}$ doping, $\sim 5 \%$ and $\sim 7.6 \%$ (as determined from XPS), a high and approximately constant value of cell attachment occurs, irrespective of annealing temperature. The platelet attachment is also reduced and has less sensitivity to anneal temperature, Fig. 4(b). With undoped a-C:H, the $\mathrm{I}_{\mathrm{D}} / \mathrm{I}_{\mathrm{G}}$ ratio is approximately constant up to $200{ }^{\circ} \mathrm{C}$, increasing with anneal temperature thereafter, indicating the expected graphitisation [13].
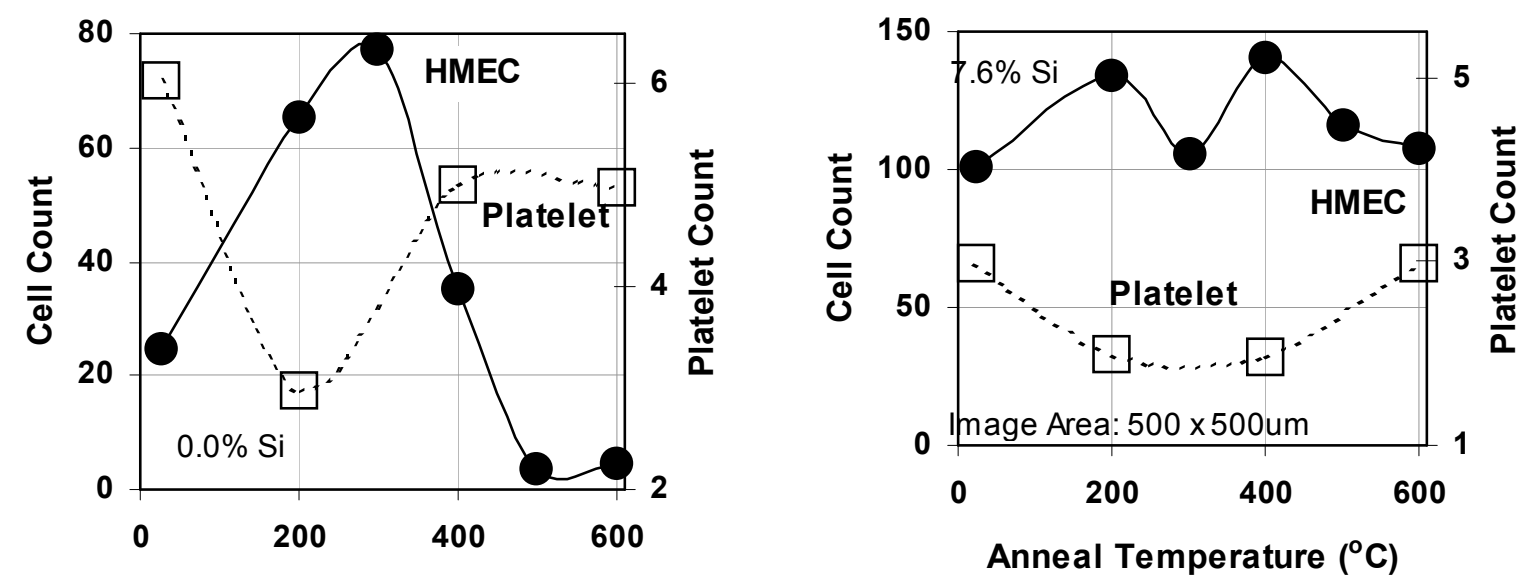

Fig. 4 (a) Platelet and Human Microvascular Endothelial Cell (HMEC) attachment to undoped a-C:H versus anneal temperature. (b) Platelet and HMEC attachment to a-C:H doped with $7.6 \%$ silicon.

With increasing silicon incorporation (unannealed), the $\mathrm{I}_{\mathrm{D}} / \mathrm{I}_{\mathrm{G}}$ ratio decreases, while the Raman slope increases, indicating increased interpenetration of the silicon and carbon networks [14], increased $\mathrm{sp}^{3}$ content (including $\mathrm{C}-\mathrm{C}, \mathrm{C}-\mathrm{H}$ and $\mathrm{C}-\mathrm{Si}$ ) [15] and increased hydrogen content [10]. At high temperatures, the hydrogen evolves from the films and competing interactions exist between carbon-Si (which promote $\mathrm{sp}^{3}$ bonding) and carbon-carbon, which leads to increased clustering and graphitisation. On annealing, the $\mathrm{I}_{\mathrm{D}} / \mathrm{I}_{\mathrm{G}}$ ratio of the a-C:H:Si ultimately rises and the temperature at which the onset of graphitisation occurs also increases with the amount of dopant. The HMEC and platelet attachment trends however do not show a direct correlation with this changing bulk structure. HMEC attachment on a-C:H is lower than a-C:H:Si and peaks at $300{ }^{\circ} \mathrm{C}$, beyond the onset of graphitisation, whereas attachment seems constant up to $600{ }^{\circ} \mathrm{C}$ on a-C:H:Si. Platelet attachment to a-C:H:Si is almost similarly unaffected by annealing and is less than for a$\mathrm{C}: \mathrm{H}$. Without silicon, it appears that an optimal film structure exists at around $200-300{ }^{\circ} \mathrm{C}$, which promotes HMEC while retarding platelet attachment. These results suggest that the compatibility of a-C: $\mathrm{H}$ is dependent on structure but that the introduction of silicon doping both improves the biocompatibility and its sensitivity to structure changes. More detailed and accurate analysis of the biocompatibility (inflammatory potential) of $\mathrm{t}-\mathrm{aC}$ films has been carried out [16] and this work is now continuing on a-C:H and a-C:H:Si.

Devices. Guidewires, up to $160 \mathrm{~cm}$ length, were investigated, with the main section consisting of stainless steel, already mandril wound into a tight spring and ended with an unwound wire tip. Films of a-C:H were deposited onto prefabricated guidewires, hung vertically from the driven electrode in a custom $2 \mathrm{~m}$ vertical chamber and process parameters varied across RF power, pressure and $\mathrm{C}_{2} \mathrm{H}_{2} / \mathrm{Ar}$ gas mixture. An a-Si:H interlayer was included between steel and a-C:H. Additional process variables included low concentration Si doping and annealing. While optimal processes could be determined, high temperature hot spots occurred along the wire leading to localised graphitisation of the a-C:H [17]. This was thought to be due to distributed inductive impedance of the wire leading to non-uniform plasma generation and, for multiple samples, the movement of wires within the gas flow. The maximum input power was therefore limited to $50 \mathrm{~W}$, compared to $\sim 400 \mathrm{~W}$ on planar substrates. A second deposition system was designed [18] to allow coaxial deposition onto an unwound wire, fed and collected by reels at either end, external to the vacuum. A 
motorised end reel pulled the wire through the chamber, at a variable rate, with the feed reel driven by the RF supply. An automatic inductive matching unit maintained optimal matching conditions as the wire batch passed from input to output. This system allows for continuous a-C:H coating but since wire winding is undertaken, post-deposition, the adhesion and flexibility of the DLC coating is much more critical. The maximum deposition power was $30 \mathrm{~W}$ at $10-20 \mathrm{mTorr}$, equivalent to $10 \mathrm{~W} \mathrm{~cm}^{-2}$, compared to $<0.5 \mathrm{~W} \mathrm{~cm}^{-2}$ for planar substrates, and the deposition rate was estimated to be between 40 and $100 \mathrm{~nm} / \mathrm{min}$. Guidewire coating friction/lubricity performance is evaluated against commercial PTFE coated guidewires by noting the withdrawal force as a function of displacement through a set of rollers. Simulated body insertion/withdrawal parameters are obtained from a similar rig where the guidewire passes through a pigskin sleeve. Two failure modes were observed after winding the a-C:H coated wire: flaking due to poor adhesion and cracking, due to low coating strength, Fig. 5. The inclusion of an a-Si:H/a-Si:C:H interlayer improved the adhesion significantly. The crack spacing was observed to increase with thickness, tending to saturation beyond $\sim 500 \mathrm{~nm}$. However, the crack length increased rapidly beyond $50 \mathrm{~nm}$ thickness traversing the wire normal to its axis. The addition of Si did little to the crack spacing/length while the use of a short anneal stage, prior to winding, improved the crack spacing.

The maximum viable anneal temperature was $300{ }^{\circ} \mathrm{C}$, beyond which the Raman characteristics indicated graphitisation, leading to severe failure. Figure 5 shows SEM images of (a) spray polymer coated control wire, (b) a-C:H coating failure, (c) a-C:H cracking detail and (d) successful DLC coating with limited cracking. Comparison of (d) with (a) highlights the improved coverage within the spring interstices necessary for better integrity, flexibility and lubricity.
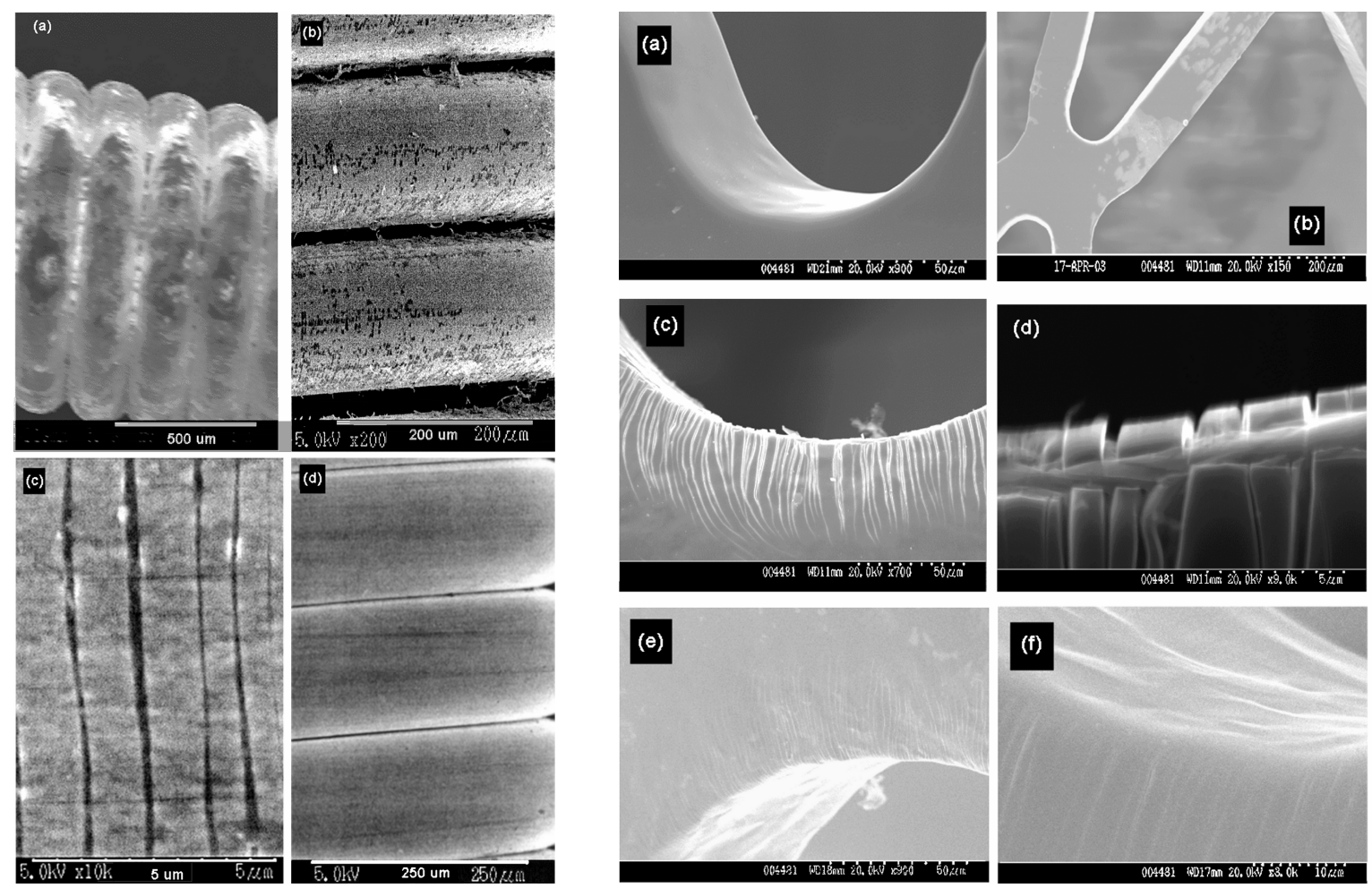

Fig. 5 (a) Polymer coated guidewire, (b) DLC coated guidewire showing adhesion and cracking failure after winding, (c) transverse cracking of DLC after winding, (d) conformal DLC coating with minimal cracking after winding. Figure 6 (a). a-C:H coating, without a-Si:H interlayer deposited onto an unexpanded stent, (b) after expansion, (c),(d) showing crack initiation, (e) (f) a$\mathrm{C}: \mathrm{H}$ coating, with a-Si:H interlayer on expanded stent.

Standard simulated-body insertion and withdrawal tests were performed to obtain an estimate of the effective coefficient of friction of DLC wires compared to the polymer. The average reduction of friction with DLC, compared to polymer, was $\sim 20 \%$ but increased to $\sim 33 \%$ for optimised films. 
Stent coating with undoped a-C:H, without interfacial layer is shown in Fig. 6(a), indicating uniformity and integrity prior to stent expansion. Expansion however leads to variation in film quality, Fig. 6(b), and crack initiation, Figs 6 (c)-(d), for films deposited without an a-Si:H interlayer. The pattern observable in Fig. 6(b) is likely due to differential charging in the SEM, indicative of possible variation in DLC quality. Raman analysis is unable to clearly detect any localised variation, returning $\mathrm{I}_{\mathrm{D}} / \mathrm{I}_{\mathrm{G}}$ ratios of $\sim 0.42$ up to 0.81 . With the introduction of an a-Si:H interfacial layer, the extent of observed cracking is reduced considerably, Figs 6 (e) - (f), and minimal variation is observed across the stent. The crack spacing and length distributions were determined and for a-C:H with interlayer, the mean values were 2.58 and $3.88 \mu \mathrm{m}$ respectively, compared to 1.43 and $6.3 \mu \mathrm{m}$, without interfacial layer. The addition of $\mathrm{Si}$, over a range of doping levels $(\leq 7 \%)$ resulted in improvements in either crack length or spacing and thus offers the possibility of further optimisation, Fig. 7.
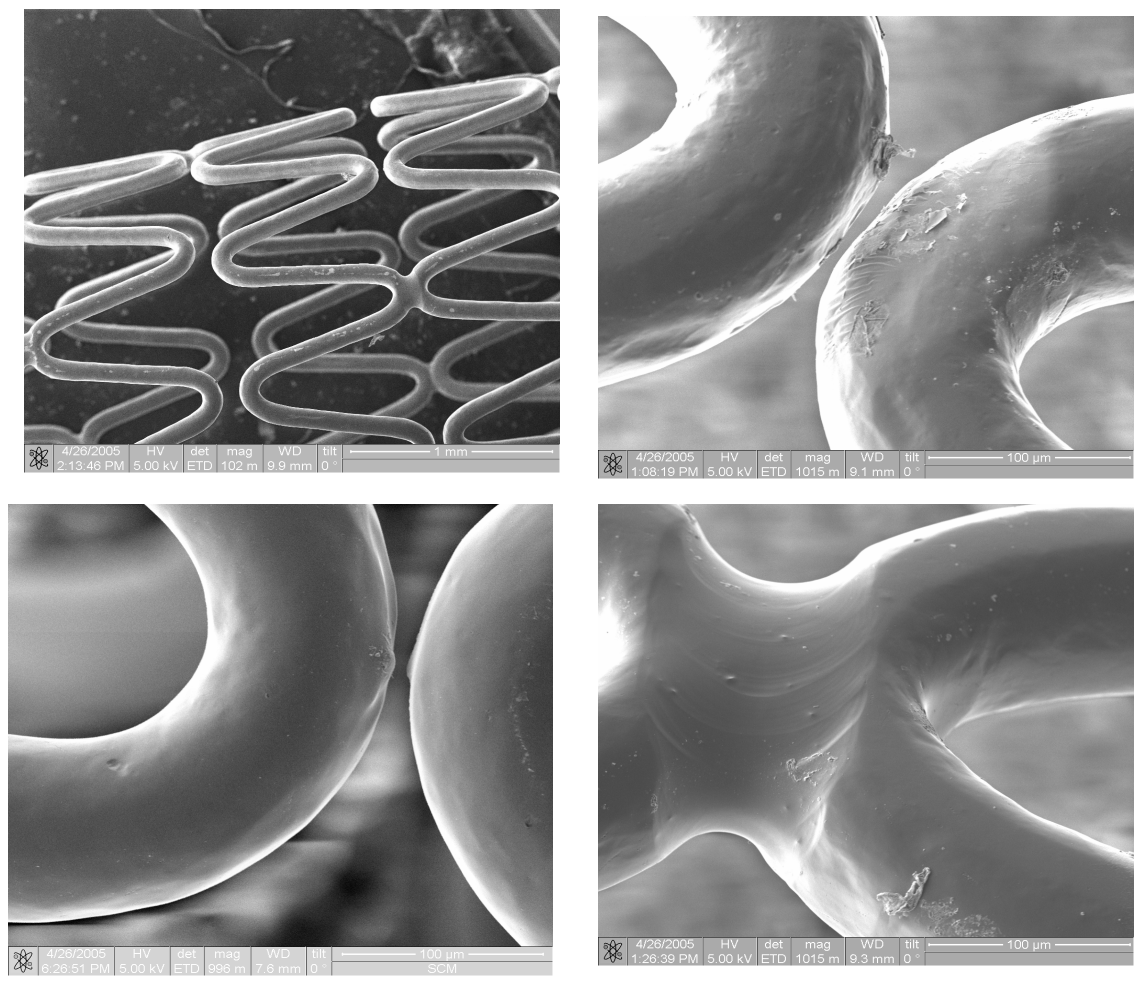

Fig. 7 Silicon doped a-C:H coating of stainless steel stents.

For these samples Raman spectra were obtained from the outer and inner stent surface coating, post expansion, Fig. 8. Due to the stent curvature and difficulty in laser positioning/focusing, the Raman signal/noise was variable and generally a poorer spectrum resulted from inner surface measurements. Across the stent, the inner surface Raman $\mathrm{I}_{\mathrm{D}} / \mathrm{I}_{\mathrm{G}}$ is higher than the outer surface, indicating a lower $\mathrm{sp}^{3} / \mathrm{sp}^{2}$ ratio, i.e. a reduction in quality, Fig. 8(a). Increasing the thickness, Fig. 8(b) indicates possible improvement of the inner surface quality.

The conformal total coverage of a stent with a-C:H presents a number of significant challenges. Considering the stent structure and dimensions, diameter of a few $\mathrm{mm}$, the component presents three faces to the plasma - the inner and outer "cylindrical" mesh surfaces and the mesh edges/stent ends. It is necessary to make electrical contact to the stent at some point, thus shadowing the deposition. Floating potential immersion restricts the DLC quality to soft polymeric because of the low energy bombardment. An RF bias driven stent will lead to a plasma sheath around its outer surface but little or no field penetration inside the mesh. Thus the inner surface coating relies on drifting of those ions that miss the outer surface. Their average energy will be reduced by collisions with neutrals, across this distance, yet sufficient randomisation of ion velocity is required to ensure conformality at mesh edges. The mechanical expansion of the stent in use is similar in effect to the guidewire winding process, subjecting the a-C:H coating to severe tensile and compressive forces. 
Quantitative testing of the stent coating uniformity with spatial precision is difficult.
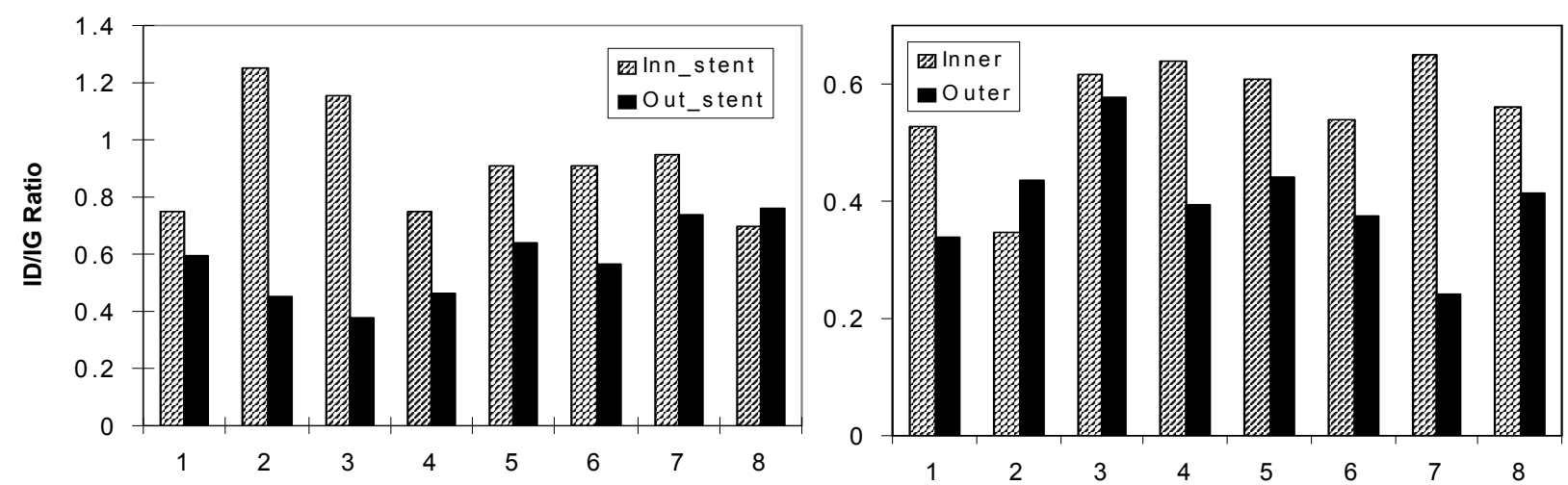

Fig. 8 Raman $\mathrm{I}_{\mathrm{D}} / \mathrm{I}_{\mathrm{G}}$ on inner and outer surfaces of Silicon doped a-C:H coating of stainless steel stents, (a) $50 \mathrm{~nm}$ and (b) $100 \mathrm{~nm}$ thickness.

\section{Conclusions}

Amorphous carbon coating of three-dimensional medical devices presents a range of additional problems, compared to flat substrates. The nature of the plasma deposition is likely to cause variations in bombarding species and energy, which leads to variation in film quality dependent on device position. Use of doping and interfacial layers can help minimise the impact of this variation. Future development will require that more detailed attention is paid to the design of device specific plasma systems and the spatial characterisation of coating quality.

\section{References}

[1] A.C. Ferrari and J. Robertson: Phys. Rev. B Vol. 61 (2000), p. 14095.

[2] D.P. Magill, A.A. Ogwu, J.A. McLaughlin, P.D. Maguire and R.W. McCullough: J. Vac. Sci. Technol. A Vol. 19 (2001), p. 2456.

[3] I. Ahmad, S.S. Roy, P.D. Maguire, P. Papakonstantinou and J.A. McLaughlin: Thin Solid Films, Vol. 482 (2005), p. 45.

[4] R. McCann, S.S. Roy, P. Papakonstantinou, I. Ahmad, P. Maguire, J.A. McLaughlin, L. Petaccia, S. Lizzit and A. Goldoni: Diam. Relat. Mater. Vol. 14 (2005), p. 1057.

[5] J.F. Zhao, P. Lemoine, Z.H. Liu, J.P. Quinn and J.A. McLaughlin: J. Phys: Condens. Mat. Vol. 12 (2000), p. 9201.

[6] P. Papakonstantinou and P. Lemoine: J. Phys: Condens. Mat. Vol. 13 (2001), p. 2971.

[7] J.F. Zhao, P. Lemoine, Z.H. Liu, J.P. Quinn, P. Maguire and J.A. McLaughlin: Diam. Relat. Mat. Vol. 10 (2001), p. 1070.

[8] A.A. Ogwu, R.W. Lamberton, P.D. Maguire and J. McLaughlin: J. Phys. D. Appl. Phys. Vol. 32 (1999), p. 981.

[9] T. Okpalugo, A. Ogwu and J. McLaughlin: Technol. Healthcare Vol. 9 (2001), p. 81.

[10] P. Papakonstantinou, J.F. Zhao, P. Lemoine, E.T. McAdams and J.A. McLaughlin: Diam. Relat. Mater. Vol. 11 (2002), p. 1074.

[11] T.I.T. Okpalugo, A.A. Ogwu, P.D. Maguire and J. McLaughlin: Biomaterials Vol. 25 (2004), p. 239.

[12] T.I.T. Okpalugo, A.A. Ogwu, P.D. Maguire, J. McLaughlin and D.G. Hirst: Diam. Relat. Mater. Vol. 13 (2004), p. 1088.

[13] J.A.D. McLaughlin, P.D. Maguire, A.A. Ogwu, R. Lamberton, J.F. Zhao and P. Lemoine: Int. J. Modern Phys. Vol. 14 (2000), p. 167.

[14] W.J. Wu and M.H. Hon: Thin Solid Films Vol. 307 (1997), p. 1.

[15] J.F. Zhao, P. Lemoine, Z.H. Liu, J.P. Quinn, P.D. Maguire and J.A.D. McLaughlin: Diam. Relat. Mater. Vol. 10 (2001), p. 1070.

[16] M. Ball, A. O'Brien, F. Dolan, G. Abbas and J.A. McLaughlin: J.Biomed.Mat.Res. Vol. 70 (2004), p. 380.

[17] J.A. McLaughlin, B. Meenan, P. Maguire and N. Jamieson: Diam. Relat. Mater. Vol. 5 (1996), p. 486.

[18] Patents GB2338716 B, US6638569 B2. 